\title{
Evidence for the Release of Bradykinin in Carcinoid Syndrome *
}

\author{
John A. Oates, $\nmid$ William A. Pettinger, and R. B. Doctor \\ (From the Division of Clinical Pharmacology, Departments of Medicine and Pharmacology, \\ Vanderbilt University School of Medicine, Nashville, Tenn.)
}

In a previous report (2), it was shown that a kinin peptide was released into the hepatic venous blood of some patients with carcinoid syndrome during flushes induced by epinephrine. A kininforming enzyme (kallikrein) was found in several carcinoid tumors. The kinin obtained from the hepatic venous blood of these patients has been further examined in the present studies. The physicochemical characteristics, enzymatic inactivation, and pharmacologic properties of this substance indicate that it is bradykinin. Studies on the formation of this kinin are also reported.

\section{Methods}

Materials. Synthetic bradykinin ${ }^{1}$ and synthetic lysylbradykinin 2 were employed. Triple-crystallized salt free lyophilized trypsin and lyophilized chymotrypsin were purchased. 3 IRC-50 (CG-50) 100 to 200 mesh, hydrogen form ${ }^{4}$ was prepared as follows: The resin was washed twice with distilled water, washed repeatedly with $3 \mathrm{~N}$ ammonium hydroxide until the $\mathrm{pH}$ exceeded 9 ( $\mathrm{pH}$ meter), washed with water, washed with $4 \mathrm{~N}$ acetic acid to reduce the $\mathrm{pH}$ below 3.5 , washed again with water,

* Submitted for publication August 20, 1965 ; accepted October 20, 1965.

Presented in part before the American Society for Clinical Investigation, May 1964 (1).

This work was supported in part by a research grant from the National Institutes of Health (USPH 5 R01 HE08668), by a Clinical Pharmacology training grant from the National Heart Institute (USPH 5 T1 HE5545), and a Clinical Research grant (5M01-Fr95-05) from the General Clinical Research Center Branch of the Division of Research Facilities and Resources, National Institutes of Health.

$\dagger$ Address requests for reprints to Dr. John A. Oates, Vanderbilt University School of Medicine, Nashville, Tenn. 37203.

1 Generously supplied by Drs. H. Schwarz and Leonard B. Achor of Sandoz Pharmaceuticals, Hanover, N. J.

2 Generously supplied by Dr. E. D. Nicholiades, Parke, Davis, and Co., Detroit, Mich.

3 Worthington Biochemical Corp., Freehold, N. J.

4 Fisher Scientific Co., Fairlawn, N. J. titrated with $3 \mathrm{~N}$ ammonium hydroxide to the appropriate $\mathrm{pH}(5.4$ or 6.0$)$, washed with water, and stored with a $0.1 \mathrm{M}$ ammonium acetate buffer of the same $\mathrm{pH}$.

Methods for purification and physicochemical characterization of the carcinoid kinin. In the previous study (2), increased amounts of a kinin peptide were found in the blood of patients with carcinoid syndrome during flushes induced with epinephrine. The present studies on the characterization of this kinin were carried out on the peptide found in hepatic venous blood samples from four of these patients (F.S., O.S., E.S., and L.C.). Amounts equivalent to 39 to $120 \mu \mathrm{g}$ of bradykinin per $100 \mathrm{ml}$ of blood were present in these samples. The blood was drawn rapidly from a catheter in the hepatic vein and immediately precipitated with ethanol, after which the kinin was separated by a cation exchange column procedure, as previously described (2). Five to $10 \%$ of the eluates from these columns was used for assay of the kinin on the rat uterus and other procedures; the remainder was frozen until further purification was undertaken.

Additional purification of this kinin was achieved by fractional elution from a weakly acidic cation exchange resin. The eluates from the initial column procedure were adjusted to $\mathrm{pH}$ 5.4. They were then passed over a 6- $\times 50-\mathrm{mm}$ column of IRC-50 ( $\mathrm{NH}_{4}^{+}$form). After the sample was applied, the column was washed with 20 $\mathrm{ml} 0.2 \mathrm{M}$ ammonium phosphate, $\mathrm{pH} 6.6$, followed by 5 $\mathrm{ml} \mathrm{H}_{2} \mathrm{O}$. Elution was carried out with $0.25 \mathrm{M}$ ammonium acetate, $\mathrm{pH}$ 8.8, which was collected in twelve 5-ml fractions. Bradykinin eluted in the several fractions surrounding the point where the $\mathrm{pH}$ of the eluate became greater than 7.5. Kinin activity of the eluates was assayed on the rat uterus, and those fractions containing kinin were pooled and evaporated in vacuo to near dryness at 35 to $40^{\circ} \mathrm{C}$ and then taken to dryness at $50^{\circ}$, with the addition of several $2-\mathrm{ml}$ volumes of $\mathrm{H}_{2} \mathrm{O}$ to speed removal of the final concentrated solution of ammonium acetate.

Gradient elution from CM-Sephadex. CarboxymethylSephadex C-25 (CM-Sephadex), 100 to 270 mesh, was prepared by allowing it to swell in $\mathrm{H}_{2} \mathrm{O}$ for 12 hours, and washing on a Buchner funnel with $0.5 \mathrm{NaOH}$ followed by $\mathrm{H}_{2} \mathrm{O}$ and then with $0.5 \mathrm{~N} \mathrm{HCl}$ followed by $\mathrm{H}_{2} \mathrm{O}$. It was then removed from the Buchner funnel, brought to pH 5.0 with $3 \mathrm{~N}$ ammonium hydroxide, and equilibrated with $0.05 \mathrm{M}$ ammonium formate, $\mathrm{pH} 5.0$. A $6-\times 90-\mathrm{mm}$ column of this resin was settled with $0.05 \mathrm{M}$ ammonium

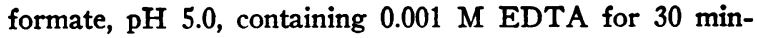


utes under a hydrostatic pressure of approximately 60 $\mathrm{cm}$ at $4^{\circ} \mathrm{C}$.

The evaporated eluate from the second IRC-50 column was then taken up in $1.4 \mathrm{ml} 0.05 \mathrm{M}$ ammonium formate, $\mathrm{pH} 5.0$, applied to the top of the column, and washed into the resin with $2 \mathrm{ml}$ of the same buffer. A gradient elution was then begun with $125 \mathrm{ml} 0.05 \mathrm{M}$ ammonium formate, $\mathrm{pH} 5.0$, in a closed mixing vessel to which $0.5 \mathrm{M}$ ammonium formate, $\mathrm{pH} 7.5$, was being added from a separate vessel $(3,4)$. Seventy fractions of $3.3 \mathrm{ml}$ were collected, and kinin content assayed on the rat uterus. As little as $1.5 \mu \mathrm{g}$ of bradykinin may be chromatographed on CM-Sephadex by this method.

After the second IRC-50 column and the CM-Sephadex gradient elution procedures to further purify the kinin initially isolated from blood, similar recoveries were found for synthetic bradykinin $(60 \%)$ and kinin activity from carcinoid blood ( $52 \%)$.

Electrophoresis. Fractions from the CM-Sephadex gradient elution, which contained kinin activity, were pooled, freeze-dried three times, and taken up in $1.5 \mathrm{ml}$ of $50 \%$ ethanol, which was concentrated to $0.1 \mathrm{ml}$ with a nitrogen jet. This sample was then applied in a narrow band $5 \mathrm{~cm}$ long $10 \mathrm{~cm}$ from the anode end of a sheet of Whatman no. 1 chromatography paper. Authentic bradykinin was added to whole blood, which was carried through the same procedures used for isolating kinin from hepatic vein blood and applied to the same paper in a similar manner. Electrophoresis of the standard and the carcinoid kinin was then carried out in a Gilson high voltage electrophoretic apparatus (5) for 2 hours at $1,000 \mathrm{v}$ and 20 to $25 \mathrm{ma}$ at $\mathrm{pH} 3.5$ in pyridine: glacial acetic acid: water $(1: 10: 289)$ buffer. The paper was dried and cut in $1-\times 7.5-\mathrm{cm}$ strips parallel to the line of origin, and the kinin on each strip eluted in De Jalon's solution and assayed on the rat uterus.

Paper chromatography. The freeze-dried eluates from CM-Sephadex gradient elutions of samples from hepatic vein blood and samples prepared similarly from normal blood to which authentic bradykinin had been added were taken up in $1.5 \mathrm{ml} 50 \%$ ethanol, evaporated to $0.1 \mathrm{ml}$ with a nitrogen jet, and applied to Whatman no. 1 chromatography paper in $5-\mathrm{cm}$ bands at the origin. The chromatogram was developed with the descending solvent $n$-butanol : glacial acetic acid: $\mathrm{H}_{2} \mathrm{O}(126: 20: 54)$ for 16 hours in an insulated chromatography cabinet, dried, and cut into $1-\times 7.5-\mathrm{cm}$ strips from the line of origin to the front. The kinin was eluted from these strips with water and assayed on the rat uterus.

To determine whether the isolation, including gradient elution and paper chromatography, sufficiently purified the kinin for amino acid analysis, we added one sample of bradykinin $(40 \mu \mathrm{g})$ to blood and carried it through the procedure. The kinin-containing eluates from the paper chromatogram were hydrolyzed in $6 \mathrm{~N} \mathrm{HCl}$ and the amino acids separated in two dimensions by chromatography and electrophoresis (5). It was found that very small amounts of other Ninhydrin positive materials were still present in the sample in addition to the bradykinin amino acids. The necessary further purification of the kinin beyond this point to permit amino acid analysis of the peptide was not feasible because of the small amounts available.

Enzymatic studies. Because of the rapidity with which bradykinin is inactivated by chymotrypsin, it was necessary to study the inactivation rate with a low enzyme concentration at reduced temperature. Authentic bradykinin, $500 \mathrm{~m} \mu \mathrm{g}$, was incubated in $1 \mathrm{ml} 0.1 \mathrm{M}$ sodium phosphate buffer, $\mathrm{pH} 7.4$, at $12^{\circ} \mathrm{C}$ for 12 minutes with 5 $\mu \mathrm{g}$ of crystalline chymotrypsin. The reaction was ended by boiling for 4 minutes, and the remaining kinin activity assayed on the rat uterus. An equivalent amount (by rat uterus assay) of carcinoid kinin was incubated under the same conditions. In separate experiments, it had been shown that inactivation was a function of time throughout the incubation period.

The conditions for the trypsin incubation were those shown by Pernow (6) to produce complete inactivation of substance P. Authentic bradykinin, $500 \mathrm{~m} \mu \mathrm{g}$ in 0.1 $\mathrm{ml}$, and $200 \mu \mathrm{g}$ of triple-crystallized trypsin in $0.1 \mathrm{ml}$ were added to $1 \mathrm{ml}$ Tyrode's solution and incubated for 60 minutes at $38^{\circ} \mathrm{C}$. The reaction was ended by adding $4 \mathrm{ml}$ boiling ethanol and boiling for 4 minutes. The samples were dried in vacuo at $35^{\circ}$ and taken up in $0.45 \%$ sodium chloride just before assay on the rat uterus. Incubation of equivalent amounts of carcinoid kinin was carried out in the same manner.

Pharmacologic studies. Kinins were quantified by comparison with submaximal doses of synthetic bradykinin on the isotonic contraction of a uterus from a virgin female rat weighing 180 to $200 \mathrm{~g}$ that had been made estrus by the subcutaneous injection of diethylstilbestrol, $100 \mu \mathrm{g}, 16$ to 24 hours before use. The uterus was suspended in a $14-\mathrm{ml}$ muscle bath containing oxygenated De Jalon's solution (7) at $28^{\circ} \mathrm{C}$.

Studies on the relaxation of the rat duodenum were carried out with the duodenum suspended in oxygenated De Jalon's solution containing atropine, $1 \mathrm{mg}$ per $\mathrm{L}$, in a 14-ml muscle bath at $30^{\circ} \mathrm{C}$.

The longitudinal muscle of a guinea pig ileum (8) was suspended in oxygenated Tyrode's solution buffered with Tris (9) at $32^{\circ} \mathrm{C}$. The depressor action of the kinins was studied in a $2.7-\mathrm{kg}$ rabbit anesthetized with $80 \mathrm{mg}$ of pentobarbital; the arterial pressures were measured with a Statham pressure transducer and recorded on a Gilson polygraph.

\section{Results}

Physicochemical characteristics of the carcinoid kinin. Initial purification of the carcinoid kinin in blood and authentic bradykinin added to blood was carried out by precipitation of the blood proteins with ethanol, extraction of lipids with ether, and a batch elution from IRC-50. This was followed by rechromatography on IRC-50 with a fractional elution. 
The eluates from the second IRC-50 column were then chromatographed on CM-Sephadex employing gradient elution with increasing $\mathrm{pH}$ and ionic strength. As can be seen in Figure 1, this system produces a clear separation of bradykinin from lysylbradykinin. The kinin isolated from the blood of a patient with carcinoid syndrome (F.S.) had elution characteristics that were similar to bradykinin. To further demonstrate the similarity of carcinoid kinin and bradykinin in this system, kinin from blood of the carcinoid patient (E.S.) was chromatographed on CMSephadex (Figure 2), and one peak of biological activity was eluted. Authentic bradykinin was then added to the pooled eluates from this peak.

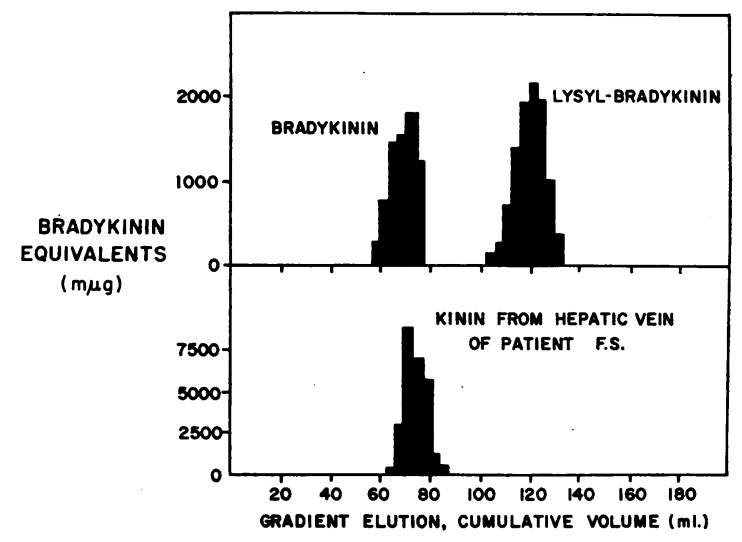

Fig. 1. ChROMATOGRAPHY OF KININS ON CARBOXYMETHYL (CM) -SEPHADEX.

These were freeze-dried and rechromatographed on CM-Sephadex. As can be seen in Figure 2, a single peak of activity was obtained when bradykinin was chromatographed together with the carcinoid kinin, indicating that the elution characteristics of the carcinoid kinin were identical to those of bradykinin and different from those of lysylbradykinin.

For paper chromatography and the following identification studies, the kinin was isolated from hepatic venous blood samples obtained during flushes from the four carcinoid patients having the highest levels of blood kinin activity. These samples were carried through the second IRC-50 column step individually, pooled, and chromatographed on CM-Sephadex. The eluates exhibiting kinin activity were pooled and freeze-dried. An equivalent amount of synthetic bradykinin was

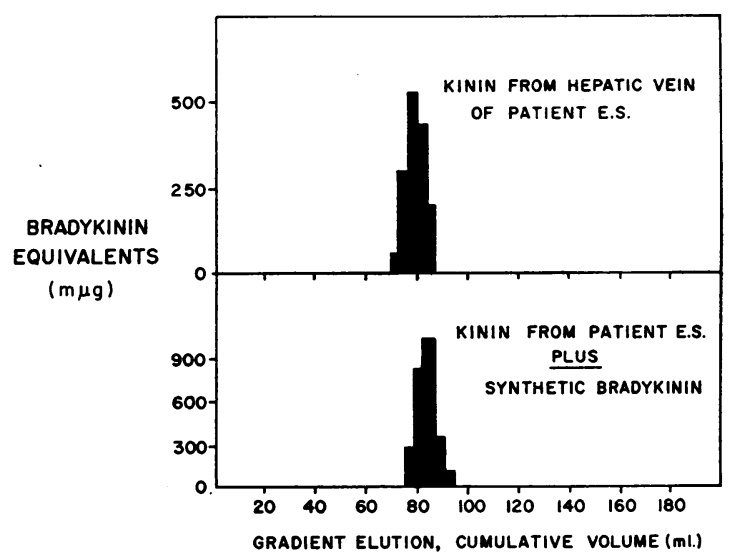

Fig. 2. Cochromatography OF BRADYKIN AND THE CARCINOID KININ ON CM-SEPHADEX.

added to the same amount of normal blood, which initially contained no measurable kinin activity, and isolated in a similar manner.

Bradykinin and the carcinoid kinin thus obtained from the CM-Sephadex eluate were then chromatographed on paper with a descending butanol : acetic acid: $\mathrm{H}_{2} \mathrm{O}$ system. As illustrated in Figure 3, the carcinoid kinin has the same $R_{t}$ (0.35) as does bradykinin.

Paper electrophoresis of similarly prepared bradykinin and carcinoid kinin was carried out at $1,000 \mathrm{v}$ in $\mathrm{pH} 3.5$ pyridine acetate buffer. The

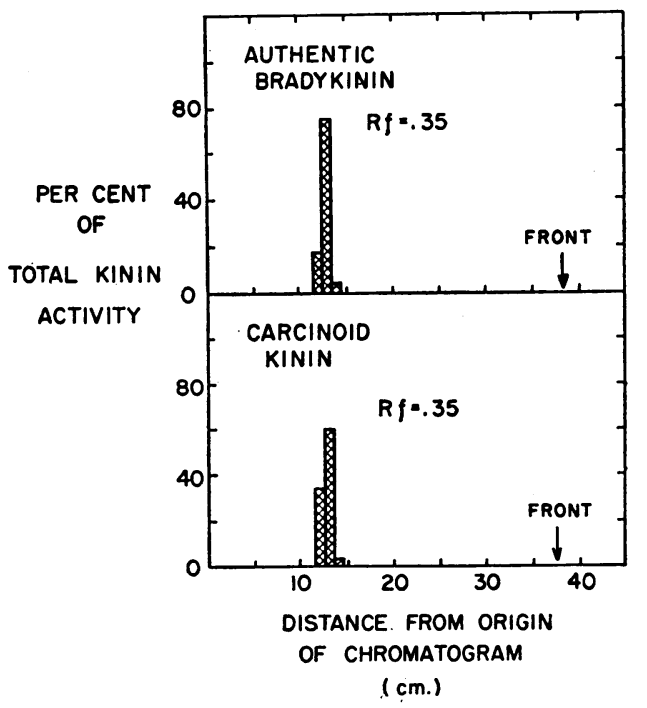

Fig. 3. Paper Chromatography OF bRADYkinin aNd THE CARCINOID KININ IN A BUTANOL: ACETIC ACID : WATER SYSTEM. 


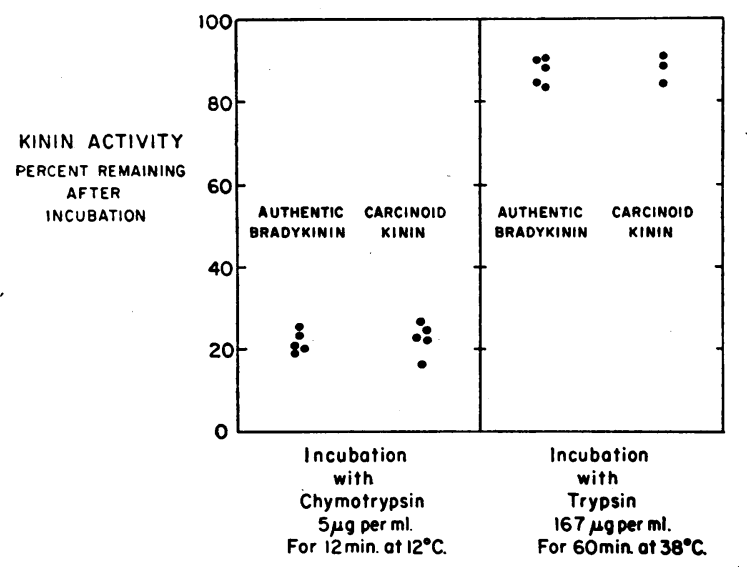

Fig. 4. CoMparison OF the RATES AT WHICH BRAdyKININ AND THE CARCINOID KININ ARE INACTIVATED BY CHYMOTRYPSIN AND TRYPSIN.

rates of migration were similar; peak activity for bradykinin was found at $15 \mathrm{~cm}$ from the origin and for the carcinoid kinin at $14 \mathrm{~cm}$ from the origin.

Enzymatic studies. The carcinoid kinin was inactivated by chymotrypsin at a rate similar to that for authentic bradykinin. At the end of the incubation, $22.0 \% \pm 1.2$ (SE) of the authentic bradykinin remained, whereas $22.7 \% \pm 1.8$ (SE) of the carcinoid kinin remained. The data from the individual incubations are presented in Figure 4.

Very little inactivation of either authentic bradykinin or carcinoid kinin occurred during incubation with trypsin (Figure 4). Complete inactivation of substance $P$ has been shown to occur during incubation with trypsin under these conditions (6).

Pharmacologic properties. A qualitative comparison of the biologic effects of the carcinoid kinin and bradykinin may be seen in Figure 5 . Similar contraction of the rat uterus and guinea pig ileum was observed, and both materials had a hypotensive action in the rabbit. Both bradykinin and the carcinoid kinin produced relaxation of the rat duodenum; substance $P$ has been shown (10) to contract this organ. If the ratio of bradykinin to carcinoid kinin activity on the rat uterus was set at 1.0, the ratio for the contraction of the guinea pig ileum was 1.15 , and for the hypotensive action in the rabbit it was 1.01. Thus, no appreciable difference in the pharmacologic effects of bradykinin and the carcinoid kinin was apparent in these systems.
The rapid formation of bradykinin from lysylbradykinin in blood. To determine whether the presence of bradykinin in blood was compatible with the finding of a kinin-forming enzyme in carcinoid tumor (2) that makes lysylbradykinin (11), we investigated the rate of conversion of lysylbradykinin to bradykinin in blood. Blood from normal humans was freshly drawn in a siliconized syringe without anticoagulant, and $30-\mathrm{ml}$ samples were placed in siliconized Erlenmeyer flasks in a $37^{\circ}$ shaker-incubator. Lysylbradykinin $(40 \mu \mathrm{g})$ was added and allowed to incubate with blood for 80 seconds, the approximate time that was estimated to elapse between the release of kallikrein into hepatic blood and the ethanol inactivation of enzymes in the withdrawn hepatic venous blood. At the end of the incubation, 4 vol of absolute ethanol was immediately added to the blood and the kinin isolated and chromatographed on CMSephadex as described above. The kinin found after incubation of lysylbradykinin had the same

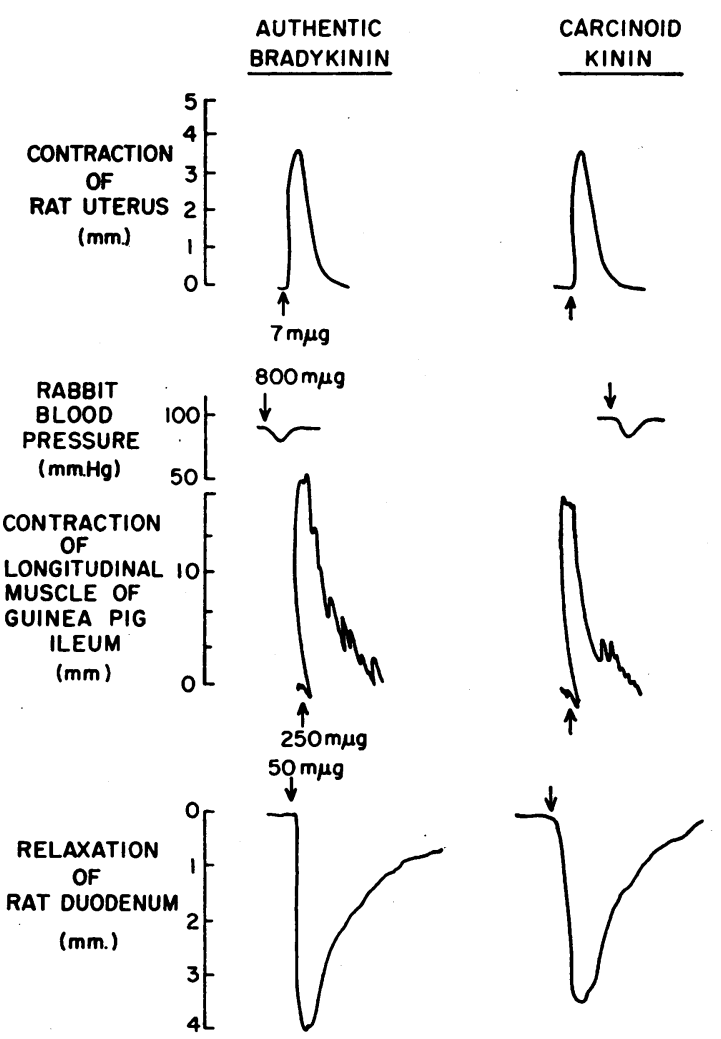

Fig. 5. QUalitative comparison OF THE PHARMaCOLOGIC ACTIONS OF THE CARCINOID KININ WITH THOSE OF BRADYKININ. 
chromatographic elution characteristics as bradykinin and was not lysylbradykinin. This finding is consistent with a rapid conversion of lysylbradykinin to bradykinin in whole blood.

In these studies it was found that lysylbradykinin was not recovered in the initial isolation procedure as readily as bradykinin. Thus, the possibility exists that small amounts of lysylbradykinin were also present in the blood of carcinoid patients, but were not detected by these procedures.

\section{Discussion}

These studies indicate that the kinin obtained from hepatic venous blood of carcinoid patients has the physicochemical properties of the nonapeptide, bradykinin. Its identity as bradykinin is further supported by the studies on its enzymatic inactivation and pharmacologic actions. Investigations of the kinin-forming enzyme (kallikrein) in carcinoid tumor (11) indicate that this enzyme, like other tissue kallikreins, forms the decapeptide lysylbradykinin. Our studies on the incubation of lysylbradykinin with fresh human blood resolved this apparent discrepancy by showing a rapid conversion of lysylbradykinin to bradykinin in blood at $37^{\circ} \mathrm{C}$. This is in agreement with the studies of Webster and Pierce demonstrating the presence of an aminopeptidase in plasma that can convert lysylbradykinin to bradykinin (12). With the development of improved methods for isolation of lysylbradykinin from blood, it should be possible to demonstrate that small amounts of this precursor are released concomitantly with bradykinin.

From the available data, it would appear that flush-provoking stimuli, such as epinephrine, act on the carcinoid tumor metastases to liberate the enzyme kallikrein into the plasma, where it acts on kininogen (a globulin) to liberate lysylbradykinin. This decapeptide is rapidly converted to bradykinin by an aminopeptidase in plasma. Further investigations of blood kallikrein levels during the flush will be necessary to verify this proposed mechanism of bradykinin release.

The release of bradykinin initiated by the welldifferentiated enterochromaffin cell tumors suggests that this mechanism of bradykinin release may also exist in normal enterochromaffin cells. Certainly, the mechanism of serotonin production is similar in normal enterochromaffin cells and car- cinoid tumors. Further studies on the exaggerated release of bradykinin and serotonin in the carcinoid syndrome may provide clues on the mechanism by which these vasoactive compounds are released physiologically.

Several vasoactive substances have now been related to the carcinoid syndrome. Excessive synthesis of 5-hydroxyindoles by these tumors is the most constant biochemical indicator of the disease. Increased histamine excretion is found in a few of these patients (13), chiefly those with gastric carcinoids (14). With the demonstration that bradykinin is released during flushes, consideration must be given to its possible role in the pathophysiology of the syndrome. Because bradykinin produces flushes resembling those occurring spontaneously in some carcinoid patients (2), it is likely that this peptide plays a role in flushes of those patients who release large amounts into the circulation. Bradykinin concentrations of over $25 \mu \mathrm{g}$ per $100 \mathrm{ml}$ of hepatic venous blood during flushes have been found in five of the eleven patients studied to date; these amounts are in the range of those required to induce peripheral vasodilatation in man (15). Because of the multihumoral potential of these tumors, it is not surprising that the appearance of the flushes seen in carcinoid syndrome may vary remarkably from patient to patient, depending on the agent or combination of agents released.

There is an abundance of data which indicates that serotonin is not the sole mediator of the paroxysms of vasodilatation seen in carcinoid patients $(2,16)$. Neither, however, is bradykinin the universal vasodilator in this syndrome. We have now studied two patients who did not release appreciable amounts of bradykinin into the hepatic venous blood during hypotensive flushing attacks. Studies in which the hepatic venous levels of both bradykinin and free plasma serotonin are measured simultaneously during flushing will be necessary to further elucidate the relationship between the various flushing patterns and specific vasoactive substances.

\section{Summary}

The kinin peptide released during carcinoid flushes was characterized with gradient elution and paper chromatography, electrophoresis, enzymatic 
inactivation rates, and studies on its pharmacologic effects. All of these investigations indicated that the carcinoid kinin was bradykinin. It is postulated that carcinoid tumors release the kininforming enzyme kallikrein in response to stimuli such as epinephrine. This enzyme splits lysylbradykinin from a protein substrate in plasma, and the lysylbradykinin is then converted rapidly to bradykinin.

The possible relation of bradykinin to the pathophysiology of the carcinoid syndrome is discussed, and it is suggested that bradykinin may be released from normal enterochromaffin cells by physiologic stimuli.

\section{Acknowledgments}

We wish to thank Drs. Leon Cunningham and Sidney Harshman for their valuable advice, and Dr. Stanley Von Hagen for his help with studies on the guinea pig ileum. The capable technical assistance of Mary $\mathrm{K}$. Davis and George D. Miller is gratefully acknowledged. The hepatic venous blood samples were obtained with the cooperation of Drs. Kenneth Melmon, Dean Mason, and Albert Sjoerdsma at the National Heart Institute.

\section{References}

1. Melmon, K., W. Lovenberg, J. A. Oates, L. Gillespie, $\mathrm{Jr}$., and A. Sjoerdsma. Implication of the kallikrein system in production of the carcinoid flush (abstract). J. clin. Invest. 1964, 43, 1308.

2. Oates, J. A., K. Melmon, A. Sjoerdsma, L. Gillespie, and D. T. Mason. Release of a kinin peptide in the carcinoid syndrome. Lancet 1964, 1, 514.

3. Elliott, D. F., E. W. Horton, and G. P. Lewis. The isolation of bradykinin, a plasma kinin from ox blood. Biochem. J. 1961, 78, 60.

4. Pierce, J. V., and M. E. Webster. Human plasma kallidins : isolation and chemical studies. Biochem. biophys. Res. Commun. 1961, 5, 353.
5. Katz, A. M., W. J. Dreyer, and C. B. Anfinsen. Peptide separation by two-dimensional chromatography and electrophoresis. J. biol. Chem. 1959, 234, 2897.

6. Pernow, B. Inactivation of substance $\mathrm{P}$ by proteolytic enzymes. Acta physiol. scand. 1955, 34, 295.

7. Gaddum, J. H., W. S. Peart, and M. Vogt. The estimation of adrenaline and allied substances in blood. J. Physiol. (Lond.) 1949, 108, 467.

8. Weiss, G. B., R. E. Coalson, and L. Hurwitz. K transport and mechanical responses of isolated longitudinal smooth muscle from guinea pig ileum. Amer. J. Physiol. 1961, 200, 789.

9. Hurwitz, L., F. Battle, and G. B. Weiss. Action of calcium antagonists, cocaine, and ethanol on contraction and potassium efflux of smooth muscle. J. gen. Physiol. 1962, 46, 315.

10. Horton, E. W. Human urinary kinin excretion. Brit. J. Pharmacol. 1959, 14, 125.

11. Melmon, K. L., W. Lovenberg, and A. Sjoerdsma. Identification of lysylbradykinin as the peptide formed in vitro by carcinoid tumor kallikrein. Clin. chim. Acta, in press.

12. Webster, M. E., and J. V. Pierce. The nature of the kallidins released from human plasma by kallikreins and other enzymes. Ann. N. Y. Acad. Sci. 1963, 104, 91.

13. Waldenström, J., B. Pernow, and H. Silwer. Case of metastasizing carcinoma (argentaffinoma?) of unknown origin showing peculiar red flushing and increased amounts of histamine and 5-hydroxytryptamine in blood and urine. Acta med. scand. 1956, 156, 73.

14. Oates, J. A., and A. Sjoerdsma. A unique syndrome associated with secretion of 5-hydroxytryptophan by metastatic gastric carcinoids. Amer. J. Med. 1962, 32, 333.

15. Fox, R. H., R. Goldsmith, D. J. Kidd, and G. P. Lewis. Brady kinin as a vasodilator in man. J. Physiol. (Lond.) 1961, 157, 589.

16. Robertson, J. I. S., W. S. Peart, and T. M. Andrews. The mechanism of facial flushes in the carcinoid syndrome. Quart. J. Med. 1962, 31, 103. 